\title{
The $K_{p}$ - Bondage And $K_{p}$ - Non Bondage Number Of Fuzzy Graphs And Graceful Graph
}

\author{
R. Jahir Hussain ${ }^{1}$ R. M. Karthik Keyan ${ }^{2}$ \\ ${ }^{1}$ Associate Professor of Mathematics, Jamal Mohamed College, Trichy, TamilNadu, India. \\ ${ }^{2}$ Research Scholar of Mathematics, Jamal Mohamed College, Trichy, Tamil Nadu, India.
}

\begin{abstract}
In this paper, we define the bondage $b_{k}(G)$, Co-bondage $b_{k c}(G)$, and Non- bondageb $_{k n}(G)$ number for any fuzzy graph and exact values for some standard graphs are found and some bounds are obtained. Moreover we also obtained relationships between $b, b_{c}, b_{n}(G)$ and $b_{k n}$. We define graph extendable to complete graph by using find extension under Co bondage arcs and we also discussed with fuzzy graceful graph.
\end{abstract}

Keywords: Minimum dominating $\operatorname{set\gamma }_{K}(G)$, maximum non-bondage number $b_{k n}(G)$,minimum bondage number $b_{k}(G)$.

\section{Introduction}

Fuzzy graph theory was introduced by A. Rosenfeld [9] in 1975. Fuzzy graph theory is now finding numerous applications in modern science and technology especially in the fields of neural networks, ex-pert systems, information theory, cluster analysis, medical diagnosis, control theory, etc. Sunil Mathew, Sunitha M.S [11] has obtained the fuzzy graph-theoretic concepts like f- bonds, paths, cycles, trees and connectedness and established some of their properties. V.R. Kulli and B. Janakiram[8] have established the non-bondage number of a graph. First we give the definitions of basic concepts of fuzzy graphs and de-ne the non-bondage and it is properties. All graphs consider here are finite, undirected, distinct labeling with no loop or multi arcs and $\mathrm{p}$ nodes and q (fuzzy) arcs. Any undefined term in this paper may be found in Harary[6]. Among the various applications of the theory of domination that have been considered, the one that is perhaps most often discussed concerns a communication network. Such a network consists of existing communication links between a fixed set of sites. The problem is to select a smallest set of sites at which to place transmitters so that every site in the network that does not have a transmitter is joined by a direct communication link to one that does have a transmitter. This problem reduces to that of finding a minimum dominating set in the graph corresponding to the network. This graph has a node representing each site and an arc between two nodes if the corresponding sites have a direct communications link joining them. To minimize the direct communication links in the network, it is non-bondage but in case we want minimum number site to control all other location sites that mean reduce the number of transmitting station. Then additional communication links should be added it is Co-bondage, we introduce the following section. T.L. Baldwin,et al[1] has given concept of Power system observability in 1993.Gerard Jennhwa Chang et al[5] have obtained Generalized power domination of graphs in 2012 .We also de ne and algorithm of power dominated set for fuzzy graph, i.e generally dominate set covered all nodes and corresponding incident arcs but here de ne dominate set have covered all nodes and edges.

\section{Preliminaries}

A fuzzy subset of a non-empty set $\mathrm{V}$ is a mapping $\sigma: \mathrm{V} \rightarrow[0,1]$. A fuzzy relation on $\mathrm{V}$ is a fuzzy subset of $\mathrm{E}(\mathrm{VxV})$. A fuzzy graph $\mathrm{G}=(\sigma, \mu)$ is a pair of function $\sigma: \mathrm{V} \rightarrow[0,1]$ and $\mu: \mathrm{VxV} \rightarrow[0,1]$, where $\mu(\mathrm{u}$, $\mathrm{v}) \leq \sigma(\mathrm{u}) \Lambda \sigma(\mathrm{v})$ for all $\mathrm{u}, \mathrm{v} \in \mathrm{V}$. The underlying crisp graph of $\mathrm{G}=(\sigma, \mu)$ is denoted by $\mathrm{G}^{*}=(\mathrm{V}, \mathrm{E})$, where $\mathrm{V}=\{\mathrm{u} \epsilon$ $\mathrm{V}: \sigma(\mathrm{u})>0\}$ and $\mathrm{E}=\{(\mathrm{u}, \mathrm{v}) \in \mathrm{VxV}: \mu(\mathrm{u}, \mathrm{v})>0\}$. The order $\mathrm{p}=\sum_{v \in D} \sigma(\mathrm{v})$. The graph $\mathrm{G}=(\sigma, \mu)$ is denoted by $\mathrm{G}$, if unless otherwise mentioned.Let be a fuzzy graph on. The degree of a vertex $u$ is $d_{G}(u)=\sum_{u \neq v} \mu(u v)$.The minimum degree of $\mathrm{G}$ is $\delta(G)=\Lambda\left\{d_{G}(u), \forall v \in V\right\}$ and the maximum degree of $\mathrm{G}$ is $\Delta(G)=\vee\left\{d_{G}(u), \forall v \in V\right\}$

The strength of connectedness between two nodes $u$ and $v$ in a fuzzy graph $G$ is define as the maximum of the strength of all paths between $\mathrm{u}$ and $\mathrm{v}$ and is denoted by $\operatorname{CONN}_{\mathrm{G}}(\mathrm{u}, \mathrm{v})$. A u-v path $\mathrm{P}$ is called a strongest path if its strength equals $\operatorname{CONN}_{G}(u, v)$. A path $P$ of length $n$ is a sequence of distinct nodes $u_{0} u_{1}$, $\mathrm{u}_{2} \ldots, \mathrm{u}_{\mathrm{n}}$ such that $\left(\mathrm{u}_{\mathrm{i}-1}, \mathrm{u}_{\mathrm{i}}\right)>0$ and degree of membership of a weakest arc is defined as its strength. If $\mathrm{u}_{0}=\mathrm{u}_{\mathrm{n}}$ and $\mathrm{n} \geq 3$, then $\mathrm{P}$ is called a cycle and it is a fuzzy cycle if there is more than one weak arc. Let $\mathrm{u}$ be a node in fuzzy graphs $G$ then

$\mathrm{N}(\mathrm{u})=\{\mathrm{v}:(\mathrm{u}, \mathrm{v})$ is strong $\operatorname{arc}\}$ is called neighborhood of $\mathrm{u}$ and

$N[u]=N(u) U\{u\}$ is called closed neighborhood of $u$. Neighborhood degree of the node is defined by the sum of the weights of the strong neighbor node of $\mathrm{u}$ is denoted by $\mathrm{d}_{\mathrm{s}}(\mathrm{u})=\sum_{v \in N(u)} \sigma(\mathrm{v})$ 


\section{Fuzzy Dominating Set}

Definition 3.1: Let $\mathrm{G}$ be a fuzzy graph and $\mathrm{u}$ be a node in $\mathrm{G}$ then there exist a node $\mathrm{v}$ such that $(\mathrm{u}, \mathrm{v})$ is a strong arc then $\mathrm{u}$ dominates $\mathrm{v}$.

Definition 3.2 : Let $\mathrm{G}$ be a fuzzy graph. A subset $\mathrm{D}$ of $\mathrm{V}$ is said to be a fuzzy dominating set if for every node $\mathrm{V}$ $\epsilon \mathrm{V} \backslash \mathrm{D}$, there exists $\mathrm{u} \epsilon \mathrm{D}$ such that $\mathrm{u}$ dominates $\mathrm{v}$.

Definition 3.3:The domination number of $\mathrm{G}$ is the minimum cardinality taken over all dominating sets in $\mathrm{G}$ and is denoted by $\gamma(\mathrm{G})$, where $\gamma(\mathrm{G})=\sum_{v \in D} \sigma(\mathrm{v})$. A dominating set with cardinality $\gamma(\mathrm{G})$ is called $\gamma$ - set of G.

Definition 3.4. Let $\mathrm{G}$ be a fuzzy graph without isolated node. A subset $\mathrm{D}$ of $\mathrm{V}$ is said to be fuzzy total dominating set if for every node $\mathrm{v}$ in $\mathrm{V}$, there exists at least one $\mathrm{u}$ in $\mathrm{D}$ such that $\mathrm{u}$ dominates $\mathrm{v}$.

Definition 3.5. The total domination number of $\mathrm{G}$ is the minimum cardinality taken over all dominating sets in $\mathrm{G}$ and is denoted by $\gamma_{\mathrm{t}}(\mathrm{G})$, where $\gamma_{\mathrm{t}}(\mathrm{G})=\sum_{v \in V} \sigma(v)$. A dominating set with cardinality $\gamma_{\mathrm{t}}(\mathrm{G})$ is called $\gamma_{\mathrm{t}}(\mathrm{G})-$ set of $\mathrm{G}$.

Definition 3.6. Let $\mathrm{G}$ be a fuzzy graph without isolated node. A subset $\mathrm{D}$ of $\mathrm{V}$ is said to be fuzzy efficient dominating set if for every node $\mathrm{v} \in \mathrm{VDD}$, there exists exact one $\mathrm{u}$ in $\mathrm{D}$ such that $\mathrm{u}$ dominates $\mathrm{v}$.

De nition 3.7. The efficient domination number of $\mathrm{G}$ is the minimum cardinality taken over all dominating sets in $\mathrm{G}$ and is denoted by $\gamma_{\mathrm{e}}(\mathrm{G})$, where $\gamma_{\mathrm{e}}(\mathrm{G})=\sum_{v \in V} \sigma(v)$.

A dominating set with cardinality $\gamma_{\mathrm{e}}(\mathrm{G})$ is called $\gamma_{\mathrm{e}}(\mathrm{G})$ - set of $\mathrm{G}$.

\section{K $K_{P}$-Dominating Set}

Let $\mathrm{G}$ be fuzzy graph and all arcs are strong arc in fuzzy graph $\mathrm{G}$, then dominate set is $\mathrm{K}_{\mathrm{P}}$ - Dominate set if it is covered (i.e means observed) all nodes and arcs and also dominate set have satisfied condition as follows i) the node (observed) at which it is placed and its incident edges and their end nodes are observed other nodes as follow.

1. Any node that is incident to an observed arc is observed.

2. Any arc joining two observed node is observed.

3. If a node is incident to total $\operatorname{arcs}$ of $\mathrm{k} \geq 2$ and if $\mathrm{k}-1$ of these arcs are observed, then all $\mathrm{k}$ of these arcs are observed.

Algorithm of $K_{\mathrm{P}}$-dominated set:

i. Take subset of $\mathrm{V}\left[\mathrm{D}^{*}\right]$ in $\mathrm{G}(\mathrm{V} ; \mathrm{E} ; \sigma, \mu)$ and consider all nodes are observed.

ii. If induced graph of [D*(subset)] is connected, then all incident $\operatorname{arcs}[s t r o n g]$ of $\mathrm{D}^{*}$ is observed by using condition 1,2 , and 3 , so observed all other nodes and arcs by $\mathrm{D}^{*}$

iii. Otherwise, using conditions and add node to $\mathrm{D}^{*}$, if any node not already in $\mathrm{D}^{*}$ which is incident to an observed arc in G.

Continuous above step ii, and iii, and until cannot find a node or edges.Then $\mathrm{D}^{*}$ is $\mathrm{K}_{\mathrm{P}}$ dominate set, in other words we define a set $\mathrm{D}^{*}$ said to be a $\mathrm{K}_{\mathrm{P}}$ - dominating set if every node and every arc in $\mathrm{G}$ is observed by D*.

The $K_{P}$ - domination number $\gamma_{K}(G)$ is the minimum cardinality of a $K_{P}$ - dominating set of G. Since a dominating set is $\mathrm{K}_{\mathrm{P}}$ - dominating set, $1 \leq \gamma_{\mathrm{K}}(\mathrm{G}) \leq \gamma(\mathrm{G})$ for all graphs $\mathrm{G}$.

Example: take figure-1 consider a node ( take $u$ is observed) is $K_{P}$-dominate set,then condition 1,3 said $\gamma_{\mathrm{K}}=1$ (ie observed all other nodes by single node)

Figure 1:

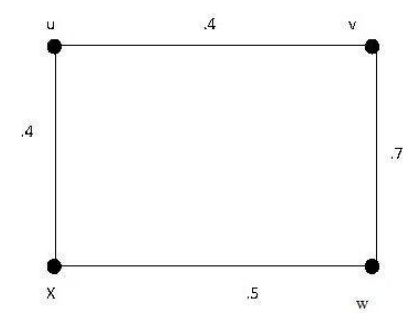




\section{Fuzzy Bondage Number}

Definition 5.1. The bondage number $\mathrm{b}(\mathrm{G})$ of a fuzzy graph $\mathrm{G}(\mathrm{V} ; \mathrm{E} ; \sigma, \mu)$ is minimum number of fuzzy arcs among all sets of $\operatorname{arcs} \mathrm{X}=(\mathrm{x}, \mathrm{y})$ sub set of $\mathrm{E}$ such that $\operatorname{CONN}_{\mathrm{G}-\mathrm{x}, \mathrm{y})}(\mathrm{u}, \mathrm{v})<\operatorname{CONN}_{\mathrm{G}}(\mathrm{u}, \mathrm{v})$ for all $\mathrm{u} \in V-\gamma(G)$ and a $v \in \gamma(\mathrm{G})$. Here $\gamma(\mathrm{G})$ represent minimum dominate set

Definition 5.2. The non-bondage number $b_{n}(G)$ of a fuzzy graph $\mathrm{G}(\mathrm{V} ; \mathrm{E} ; \sigma, \mu)$ is maximum number of fuzzy arcs among all sets of $\operatorname{arcs} \mathrm{X}=(\mathrm{x}, \mathrm{y})$ sub set of $\mathrm{E}$ such thatCONN $\mathrm{G}_{-(\mathrm{x} ; \mathrm{y})}(\mathrm{u} ; \mathrm{v})=\mathrm{CON} \mathrm{N}_{\mathrm{G}}(\mathrm{u} ; \mathrm{v})$ for all $\mathrm{u} \in V-$ $\gamma(G)$ and a $\mathrm{v} \in \gamma(\mathrm{G})$. Here $\gamma(\mathrm{G})$ represent minimum dominate set.

Definition 5.3. The t-bondage number $\mathrm{b}_{\mathrm{t}}(\mathrm{G})$ of a fuzzy graph $\mathrm{G}(\mathrm{V} ; \mathrm{E} ; \sigma, \mu)$ is minimum number of fuzzy arcs among all sets of $\operatorname{arcs} \mathrm{X}=(\mathrm{x}, \mathrm{y})$ sub set of $\mathrm{E}$ such that $\mathrm{CONN}_{\mathrm{G}-(\mathrm{x}, \mathrm{y})}(\mathrm{u}, \mathrm{v})<\mathrm{CONN}_{\mathrm{G}}(\mathrm{u}, \mathrm{v})$ for all $\mathrm{u} \in V-\gamma_{t}(G)$ and a $v \in \gamma_{t}(\mathrm{G})$. Here $\gamma_{t}(\mathrm{G})$ represent minimum dominate set.

Definition 5.4. The t-non-bondage number $\mathrm{b}_{\mathrm{tn}}(\mathrm{G})$ of a fuzzy graph $\mathrm{G}(\mathrm{V} ; \mathrm{E} ; \sigma, \mu)$ is maximum number of fuzzy arcs among all sets of $\operatorname{arcs} X=(\mathrm{x}, \mathrm{y})$ sub set of $\mathrm{E}$ such that $\mathrm{CON} \mathrm{N}_{\mathrm{G}-(\mathrm{x} ; \mathrm{y})}(\mathrm{u} ; \mathrm{v})=\mathrm{CON} \mathrm{N}_{\mathrm{G}}(\mathrm{u} ; \mathrm{v})$ for all $\mathrm{u} \in V-$ $\gamma_{t}(G)$ and a $\mathrm{v} \in \gamma_{t}(\mathrm{G})$. Here $\gamma_{t}(\mathrm{G})$ represent minimum dominate set.

Definition 5.5. The e-bondage number $\mathrm{b}_{\mathrm{e}}(\mathrm{G})$ of a fuzzy graph $\mathrm{G}(\mathrm{V} ; \mathrm{E} ; \sigma, \mu)$ is minimum number of fuzzy arcs among all sets of $\operatorname{arcs} \mathrm{X}=(\mathrm{x}, \mathrm{y})$ sub set of $\mathrm{E}$ such that $\operatorname{CONN}_{\mathrm{G}-\mathrm{(x}, \mathrm{y})}(\mathrm{u}, \mathrm{v})<\operatorname{CONN}_{\mathrm{G}}(\mathrm{u}, \mathrm{v})$ for all $\mathrm{u} \in V-\gamma_{e}(G)$ and a $\mathrm{v} \in \gamma_{e}(\mathrm{G})$. Here $\gamma_{e}(\mathrm{G})$ represent minimum dominate set.

Definition 5.6. The e-non-bondage number $b_{\mathrm{en}}(\mathrm{G})$ of a fuzzy graph $\mathrm{G}(\mathrm{V} ; \mathrm{E} ; \sigma, \mu)$ is maximum number of fuzzy arcs among all sets of $\operatorname{arcs} X=(\mathrm{x}, \mathrm{y})$ sub set of $\mathrm{E}$ such that $\operatorname{CONN}_{\mathrm{G}-\mathrm{x} ; \mathrm{y})}(\mathrm{u} ; \mathrm{v})=\mathrm{CON} \mathrm{N}_{\mathrm{G}}(\mathrm{u} ; \mathrm{v})$ for all $\mathrm{u} \in V-$ $\gamma_{e}(G)$ and a $\mathrm{v} \in \gamma_{e}(\mathrm{G})$. Here $\gamma_{e}(\mathrm{G})$ represent minimum dominate set.

Definition 5.7. The co - bondage number $b_{c}(G)$ of fuzzy graph $\mathrm{G}(\mathrm{V} ; \mathrm{E} ; \sigma, \mu)$ is minimum number of fuzzy arcs required to add graph $\mathrm{G}$ such that $\gamma(\mathrm{G}+\mathrm{e})<\gamma(\mathrm{G})$ and generally $\mu(\mathrm{e}=(\mathrm{u}, \mathrm{v}))=\mathrm{CONN}_{\mathrm{G}}(\mathrm{u}, \mathrm{v})$. Otherwise special case $\mu(\mathrm{e})=\operatorname{Max}\{(\mathrm{u} ; \mathrm{w}) ;(\mathrm{u} ; \mathrm{x})\}$ or $\operatorname{Max}\{(\mathrm{w} ; \mathrm{v}) ;(\mathrm{x} ; \mathrm{v})\}$, for any $\mathrm{u}, \mathrm{v}$ in $\mathrm{V}$.

\section{VI. $K_{p}$ - Bondage Number}

\section{Figure 2:}

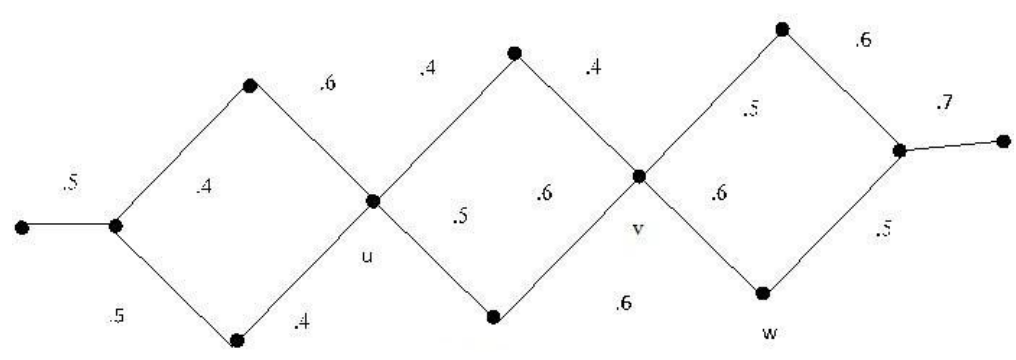

Definition 6.1. The $\mathrm{K}_{\mathrm{P}}$ - bondage number $\mathrm{b}_{\mathrm{K}}(\mathrm{G})$ of a fuzzy graph $\mathrm{G}(\mathrm{V} ; \mathrm{E} ; \sigma, \mu)$ is minimum number of fuzzy arcs among all sets of $\operatorname{arcs} \mathrm{X}=(\mathrm{x}, \mathrm{y})$ sub set of $\mathrm{E}$ such that

$\mathrm{CONN}_{\mathrm{G}-(\mathrm{x} ; \mathrm{y})}(\mathrm{u} ; \mathrm{v})<\operatorname{CONN}_{\mathrm{G}}(\mathrm{u} ; \mathrm{v})$ for all $\mathrm{u} \in \mathrm{V}-\gamma_{\mathrm{K}}(\mathrm{G})$ and a $\mathrm{v} \in \gamma_{\mathrm{K}}(\mathrm{G})$. Here $\gamma_{\mathrm{K}}(\mathrm{G})$ represent minimum dominate set

Example: take figure- $2 \mathrm{u}$ and $\mathrm{v}$ are $\mathrm{K}_{\mathrm{P}}$-dominate set $\left(\gamma_{\mathrm{K}}=2\right)$ and if remove three arcs from $\mathrm{G}$ then $\left(\gamma_{\mathrm{K}}=3\right)$, sob $_{\mathrm{K}}$ $=3$ in fig-3

Figure 3: $\mathrm{K}_{\mathrm{P}}$-bondage

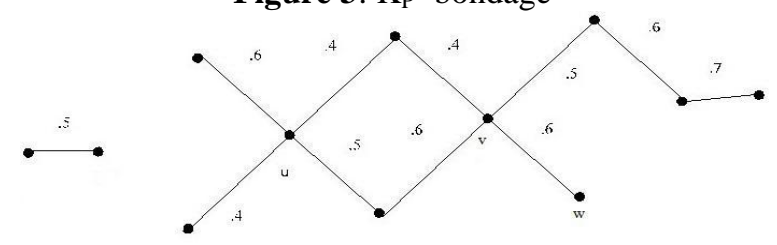

Definition 6.2. The $\mathrm{K}_{\mathrm{P}}$-non-bondage number $\mathrm{b}_{\mathrm{Kn}}(\mathrm{G})$ of a fuzzy graph $\mathrm{G}(\mathrm{V} ; \mathrm{E} ; \sigma, \mu)$ is maximum number of fuzzy arcs among all sets of $\operatorname{arcs} \mathrm{X}=(\mathrm{x}, \mathrm{y})$ sub set of $\mathrm{E}$ such that 
$\operatorname{CONN}_{\mathrm{G}-(\mathrm{x} ; \mathrm{y})}(\mathrm{u} ; \mathrm{v})=\operatorname{CONN}_{\mathrm{G}}\left(\mathrm{u}\right.$; v)for all $\mathrm{u} \in \mathrm{V}-\gamma_{k}(\mathrm{G})$ and a $\mathrm{v} \in \gamma_{k}(\mathrm{G})$.Here $\gamma_{k}(\mathrm{G})$ represent minimum dominate set

Example: take fig-2 and $\mathrm{u}$,and $\mathrm{v}$ are $\mathrm{K}_{\mathrm{P}}$-dominate $\operatorname{set}\left(\gamma_{\mathrm{K}}=2\right)$,if remove two arcs from $\mathrm{G}$ also $\left(\gamma_{\mathrm{K}}=2\right)$ in fig- 4 ,so $b_{\mathrm{Kn}}=2$

Figure 4: $\mathrm{K}_{\mathrm{P}}$ - non bondage

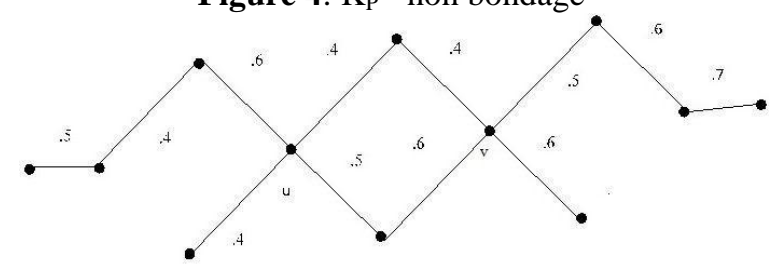

Definition 6.3. The $\mathrm{K}_{\mathrm{P}}-\mathrm{Co}$ - bondage number $\mathrm{b}_{\mathrm{Kc}}(\mathrm{G})$ of fuzzy graph $\mathrm{G}(\mathrm{V} ; \mathrm{E} ; \sigma, \mu)$ is minimum number of fuzzy arcs (observed arcs) required to add graph $\mathrm{G}$ such that $\gamma_{\mathrm{K}}(\mathrm{G}+\mathrm{e})<\gamma_{\mathrm{K}}(\mathrm{G})$ and

$\mu(\mathrm{e})=\operatorname{Max}\{(\mathrm{u} ; \mathrm{w}) ;(\mathrm{u} ; \mathrm{x})\}$ or $\operatorname{Max}\{(\mathrm{w} ; \mathrm{v}) ;(\mathrm{x} ; \mathrm{v})\}$, for any $\mathrm{u}, \mathrm{v}$ in V.Here $\gamma_{\mathrm{K}}(\mathrm{G})$ represent minimum dominate set

Example: takefigure- $2 \mathrm{u}$ and $\mathrm{V}$ are $\mathrm{K}_{\mathrm{P}}$-dominate set $\left(\gamma_{\mathrm{K}}=2\right)$ and if add one arc then $\left(\gamma_{\mathrm{K}}=1\right)$,so $\mathrm{b}_{\mathrm{Kc}}=1$

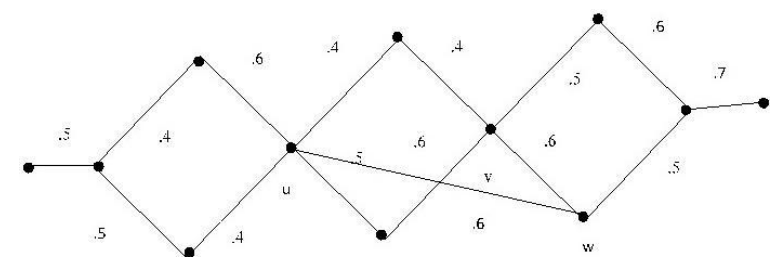

VII. Main Results

Theorem 7.1. For any fuzzy graph G,

$$
b_{\mathrm{Kn}}(\mathrm{G})=\mathrm{q}-\mathrm{p}+\gamma_{\mathrm{k}}(\mathrm{G})
$$

where $\mathrm{q}$ is total number of fuzzy arcs and $\mathrm{p}$ is total number of node.

Proof.

Let $\mathrm{D}$ be a minimal dominated set of $\mathrm{G}$ and its denote by $\gamma_{\mathrm{K}}(\mathrm{G})$. For each node $\mathrm{v} \in \mathrm{V}$ - D choose exactly one strong arc which is incident to node $\mathrm{v}$ and to a node in $\mathrm{D}$. Let $\mathrm{E} 1$ be the set of all such arcs. The clearly $\mathrm{E}-\mathrm{E} 1$ is $a b_{K n}(G)$ set of $G \cdot b_{K n}(G)=q-\left(p-\gamma_{K}(G)\right) b_{K n}(G)=q-p+\gamma_{K}(G)$.

Proposition 7.2. If $\mathrm{P}_{\mathrm{p}}$ is a path with $\mathrm{p} \geq 2$ nodes, then $\mathrm{b}_{\mathrm{Kn}}\left(\mathrm{P}_{\mathrm{p}}\right)=0$.

Proposition 7.3. If $C_{p}$ is a cycle with $p \geq 3$ nodes, then $b_{K n}\left(C_{p}\right)=1$.

Proposition 7.4. If Kp is a fuzzy complete graph $\mathrm{p} \geq 2$ nodes, then $b_{K n}(K p)=\frac{(p-1)(p-2)}{2}$

Proposition 7.5. If $K_{2 ; n}$ is a fuzzy complete bipartite graph , then $b_{K n}\left(K_{2 ; n}\right)=n-1$

Proposition 7.6. If $\mathrm{W}_{\mathrm{p}}$ is a wheel with $\mathrm{p} \geq 4$ nodes, then $\mathrm{b}_{\mathrm{Kn}}\left(\mathrm{W}_{\mathrm{p}}\right)=\mathrm{p}-1$.

Proposition 7.7. For any fuzzy tree $T, b_{K n}(T)=\gamma_{K}(T)-1$.

Theorem 7.8.

If $\mathrm{G}$ be a cycle graph then

with $\mathrm{p} \geq 4$

$$
b_{K n}(\bar{G})+b_{K n}(G) \leq \frac{p(p-3)}{2}
$$

Proof

By theorem $7.1 \mathrm{~b}_{\mathrm{kn}}(\mathrm{G})=\mathrm{q}-\mathrm{p}+\gamma_{k}(G)$

$\left.\mathrm{b}_{\mathrm{kn}}(\bar{G})=\bar{q}-\mathrm{p}+\gamma_{k} \overline{(G}\right)$

$$
\begin{aligned}
& b_{K n}(\bar{G})+b_{K n}(G)=q-p+\gamma_{k}+\bar{q}-p+\gamma_{k}(\bar{G}) \\
& =q+\bar{q}-2 p+\gamma_{k}+\gamma_{k}(\bar{G}) \\
& =\frac{p(p-1)}{2}-2 p+\gamma_{k}+\gamma_{k}(\bar{G}) \\
& \leq \frac{p(p-1)}{2}-2 p-p
\end{aligned}
$$


$\leq \frac{p(p-3)}{2}$.

Theorem 7.9

For any fuzzy graph G,

$$
b_{K n}(\bar{G})+b_{K n}(G) \leq \frac{(p-1)(p-2)}{2}
$$

Proof : Sinceb $_{\mathrm{kn}} \leq q-\Delta_{n}$ then

$$
\begin{aligned}
b_{K n}(\bar{G})+b_{K n}(G) & \leq \bar{q}+q-\left(\Delta_{n}+\delta_{n}\right) \\
& =\frac{(p(p-1))}{2}-\left(\Delta_{n}+\delta_{n}\right)
\end{aligned}
$$

Theorem 7.10 For any fuzzy graph G

$$
\begin{gathered}
\leq \frac{(p(p-1))}{2}-(p-1) \\
\leq \frac{((p-2)(p-1))}{2}
\end{gathered}
$$

$$
b_{\mathrm{k}}(\mathrm{G}) \leq b_{k n}(G)+1(4)
$$

Theorem 7.11. For any fuzzy graph G,

$$
b_{\mathrm{kn}}(\mathrm{G}) \leq \mathrm{b}_{\mathrm{n}}(\mathrm{G})
$$

Theorem 7.12: If $\mathrm{G}$ be a cycle graph then

Proof: by theorem 7.10

$$
b_{K}(\bar{G})+b_{K}(G) \leq \frac{p(p-3)}{2}+2
$$

$\mathrm{b}_{\mathrm{k}}(\mathrm{G}) \leq b_{k n}(G)+1$

$b_{K}(\bar{G})+b_{K}(G) \leq b_{K n}(\bar{G})+b_{K n}(G)+2$

By theorem 7.8

$b_{K}(\bar{G})+b_{K}(G) \leq \frac{p(p-3)}{2}+2$

Theorem 7.13. Any graph $\mathrm{G}$,

$$
b_{K}(\bar{G})+b_{K}(G) \leq \frac{(p-1)(p-2)}{2}+2
$$

Theorem 7.14. If $\mathrm{G}$ be a fuzzy tree then

$$
b_{K n}(\bar{G})+b_{K n}(G) \geq \gamma_{k}(\bar{G})+\gamma_{k}(G)-2 \quad \text { if } \mathrm{p} \geq 4
$$

Proof $; b_{K n}(G) \geq \gamma_{k}(G)-1$, then

$b_{K n}(\bar{G})+b_{K n}(G) \geq \gamma_{k}(\bar{G})+\gamma_{k}(G)-2$.

Theorem 7.15. For any fuzzy graph $\mathrm{G}$ without isolated nodes and $\Delta_{n}(G)=p-1$.

$$
b_{t n}(G)=q-p+1
$$

Proof :. let $\mathrm{G}$ be a graph with a node u such that $\operatorname{deg} \mathrm{u}=\Delta_{n}(G)=p-1$.then there exit a node such that $\mathrm{e}=\mathrm{uv} \in$ E. Thus $u, v$ is a total dominating set of $G$. let $X$ be the set of arcs which not strong of $u$. Then clearly $b_{t n}=|X|=$ $\mathrm{q}-\Delta_{n}(G)=\mathrm{q}-\mathrm{p}+1$.

Theorem 7.16. For any graph $\mathrm{G}$ without isolated nodes,

$$
b_{t n} \leq q-\Delta_{n}(G)
$$

Proof : this follow from (9) and that fact that $\Delta_{n} \leq p-1$.

Theorem 7.17. Let $\mathrm{G}$ be a graph without isolated nodes. If $\mathrm{H}$ is a subgraph of $\mathrm{G}$, then

$$
\mathrm{b}_{\mathrm{tn}}(\mathrm{H}) \leq \mathrm{b}_{\mathrm{tn}}(\mathrm{G}) \text { : }
$$


Proof. Every total non bondage set of $\mathrm{H}$ is a total non-bondage set of G. Thus(11)holds.

Theorem 7.18. For any fuzzy graph G,

$$
b_{e n}=q-p+\gamma_{e}(G)
$$

where $\mathrm{q}$ is total number of fuzzy arcs and $\mathrm{p}$ is total number of node.

Proof. Let $\mathrm{D}$ be a minimal dominated set of $\mathrm{G}$ and its denote by $\gamma_{e}(\mathrm{G})$. For each node $\mathrm{v} \in \mathrm{V}-\mathrm{D}$ choose exactly one strong arc which is incident to node $v$ and to a node in $D$. Let $E_{1}$ be the set of all such arcs. The clearly $E_{-} E_{1}$ is a $b_{\mathrm{tn}}(\mathrm{G})$ set of $\mathrm{G} \cdot \mathrm{b}_{\mathrm{en}}(\mathrm{G})=\mathrm{q}-\left(\mathrm{p}-\gamma_{\mathrm{e}}(\mathrm{G})\right)$

$b_{e n}(G)=q-p+\gamma_{\mathrm{e}}(G)$

Proposition 7.19. If $\mathrm{K}_{\mathrm{m} ; \mathrm{n}}$ is a fuzzy complete bipartite graph with $2 \leq \mathrm{m} \leq \mathrm{n}$, then

$$
\mathrm{b}_{\mathrm{en}}\left(\mathrm{K}_{\mathrm{m} ; \mathrm{n}}\right)=\mathrm{mn}-\mathrm{m}-\mathrm{n}+2
$$

Proof. Let $\mathrm{K}_{\mathrm{m} ; \mathrm{n}}$ be a complete bipartite graph with $2 \leq \mathrm{m} \leq \mathrm{n}$ then $\mathrm{q}=\mathrm{mn}, \mathrm{p}=\mathrm{m}+\mathrm{n}$ and $\gamma_{\mathrm{e}}(\mathrm{G})=2$ hence by theorem 7.18 , the result

Theorem 7.20: For graph fuzzy $\mathrm{G}$ and fuzzy complement $\bar{G}$ with no isolated nodes,

$$
b_{K n}(\bar{G})+b_{K n}(G) \leq \frac{(p-1)(p-2)}{2}
$$

\section{Other Domination}

Definition 8.1. (Independent Domination) A domination set $D$ of a graph $G=(V, E)$ is an independent dominating set if the induced subgraph $\langle D\rangle$ has no edges or no strong arc between any pair of $\mathrm{D}$ in $\mathrm{G}$. The independent domination number $\mathrm{i}(\mathrm{G})$ of a graph $\mathrm{G}$ is the minimum cardinality of an independent dominating set.since independent set is dominate set so $\gamma(\mathrm{G}) \leq \mathrm{i}(\mathrm{G})$.

Definition 8.2. The bondage number $b_{i}(G)$ of a fuzzy graph $\left.\mathrm{G}(\mathrm{V} ; \mathrm{E} \sigma, \mu)\right)$ is minimum number of fuzzy arcs among all sets of $\operatorname{arcs} \mathrm{X}=(\mathrm{x}, \mathrm{y})$ sub set of $\mathrm{E}$ such that

$\mathrm{CONN}_{\mathrm{G}-(\mathrm{x} ; \mathrm{y})}(\mathrm{u} ; \mathrm{v})<\mathrm{CONN}_{\mathrm{G}}(\mathrm{u} ; \mathrm{v})$ for all $\mathrm{u} \in \mathrm{V}-\mathrm{i}(\mathrm{G})$ and $\mathrm{a} \mathrm{v} \in \mathrm{i}(\mathrm{G})$. Here $\mathrm{i}(\mathrm{G})$ represent minimum dominate set

Definition 8.3. The non-bondage number $b_{\text {in }}(G)$ of a fuzzy graph $\left.G(V ; E \sigma, \mu)\right)$ is maximum number of fuzzy arcs among all sets of $\operatorname{arcs} \mathrm{X}=(\mathrm{x}, \mathrm{y})$ sub set of $\mathrm{E}$ such that

$\mathrm{CON} \mathrm{N}_{\mathrm{G}-(\mathrm{x} ; \mathrm{y})}(\mathrm{u} ; \mathrm{v})=\mathrm{CONN}_{\mathrm{G}}(\mathrm{u} ; \mathrm{v})$ for all $\mathrm{u} \in \mathrm{V}-\mathrm{i}(\mathrm{G})$ and $\mathrm{a} \mathrm{v} \in \mathrm{i}(\mathrm{G})$. Here $\mathrm{i}(\mathrm{G})$ represent minimum dominate set

Theorem 8.4. For any fuzzy graph $\mathrm{G}$,

$$
\mathrm{b}_{\mathrm{n}}(\mathrm{G})=\mathrm{q}-\mathrm{p}+\gamma(\mathrm{G})
$$

where $\mathrm{q}$ is total number ofuzzy arcs and $\mathrm{p}$ is total number of node.

Theorem 8.5. For any fuzzy graph $\mathrm{G}$,

$$
b_{\text {in }}(G) \leq q-p+i(G)
$$

where $\mathrm{q}$ is total number of fuzzy arcs and $\mathrm{p}$ is total number of node.

Corollary 8.6. If $\mathrm{C}_{\mathrm{p}}$ is a fuzzy cycle with $\mathrm{p} \geq 4$ nodes, then $\mathrm{b}_{\mathrm{in}}\left(\mathrm{P}_{\mathrm{p}}\right)=\left\lceil\frac{P}{3}\right\rceil$ 
Theorem 8.7. If $\mathrm{Kp}$ is a fuzzy complete graph $\mathrm{p} \geq 3$ nodes, then $\operatorname{bin}(\mathrm{Kp})=\frac{(P-1)(P-2)}{2}$

Theorem 8.8. If $\mathrm{W}_{\mathrm{p}}$ is a fuzzy wheel with $\mathrm{p} \geq 4$ nodes, then $\mathrm{b}_{\text {in }}\left(\mathrm{W}_{\mathrm{p}}\right)=\mathrm{p}-2+\left\lceil\frac{P}{3}\right\rceil$

Definition 8.9. (Connected Domination) A connected dominating set D to be a dominating set D whose induced subgraph $\langle D\rangle$ is connected. The connected domination number $\gamma_{c}(\mathrm{G})$ of a connected graph $\mathrm{G}$ is the minimum cardinality of a connected dominating set.

Definition 8.2. The bondage number $\mathrm{b}_{\mathrm{co}}(\mathrm{G})$ of a fuzzy graph $\left.\mathrm{G}(\mathrm{V} ; \mathrm{E} \sigma, \mu)\right)$ is minimum number of fuzzy arcs among all sets of $\operatorname{arcs} \mathrm{X}=(\mathrm{x}, \mathrm{y})$ sub set of $\mathrm{E}$ such that

$\mathrm{CONN}_{\mathrm{G}-(\mathrm{x} ; \mathrm{y})}(\mathrm{u} ; \mathrm{v})<\mathrm{CONN}_{\mathrm{G}}(\mathrm{u} ; \mathrm{v})$ for all $\mathrm{u} \in \mathrm{V}-\gamma_{c}(\mathrm{G})$ and a $\mathrm{v} \in \gamma_{c}(\mathrm{G})$. Here $\gamma_{c}(\mathrm{G})$ represent minimum dominate set.

Definition 8.3. The non-bondage number $b_{c o-n}(G)$ of a fuzzy graph $\left.G(V ; E \sigma, \mu)\right)$ is maximum number of fuzzy arcs among all sets of $\operatorname{arcs} \mathrm{X}=(\mathrm{x}, \mathrm{y})$ sub set of $\mathrm{E}$ such that

$\mathrm{CON} \mathrm{N}_{\mathrm{G}-(\mathrm{x} ; \mathrm{y})}(\mathrm{u} ; \mathrm{v})=\mathrm{CONN}_{\mathrm{G}}(\mathrm{u} ; \mathrm{v})$ for all $\mathrm{u} \in \mathrm{V}-\gamma_{c}(\mathrm{G})$ and a $\mathrm{v} \in \gamma_{c}(\mathrm{G})$. Here $\gamma_{c}(\mathrm{G})$ represent minimum dominate set

Theorem 8.12. For any fuzzy graph G,

$$
b_{c o}(G)+\chi(G) \leq q+2
$$

and this bound is sharp.

Theorem 8.13. For any fuzzy graph $\mathrm{G}$

$$
b_{c o}(G)+\kappa(G) \leq q+1
$$

this bound is sharp.

Definition 8.14. (Clique domination) A domination set $\mathrm{D}$ of a graph $\mathrm{G}=(\mathrm{V}, \mathrm{E})$ is a clique dominating set if the induced subgraph $\langle D\rangle$ is a complete graph. The connected domination number $\gamma_{c l}(\mathrm{G})$ of a connected graph $\mathrm{G}$ is the minimum cardinality of a connected dominating set.

Definition 8.15. The bondage number $\mathrm{b}_{\mathrm{cl}}(\mathrm{G})$ of a fuzzy graph $\left.\mathrm{G}(\mathrm{V} ; \mathrm{E}, \sigma, \mu)\right)$ is minimum number of fuzzy arcs among all sets of $\operatorname{arcs} X=(x, y)$ sub set of $E$ such that

$\mathrm{CONN}_{\mathrm{G}-(\mathrm{x} ; \mathrm{y})}(\mathrm{u} ; \mathrm{v})<\mathrm{CONN}_{\mathrm{G}}(\mathrm{u} ; \mathrm{v})$ for all $\mathrm{u} \in \mathrm{V}-\gamma_{c l}$ and a $\mathrm{v} \in \gamma_{c l}(\mathrm{G})$. Here $\gamma_{c l}(\mathrm{G})$ represent minimum dominate set

Definition 8.16. The non-bondage number $b_{\operatorname{cln}}(G)$ of a fuzzy graph $\left.G(V ; E, \sigma, \mu)\right)$ is maximum number of fuzzy arcs among all sets of $\operatorname{arcs} \mathrm{X}=(\mathrm{x}, \mathrm{y})$ sub set of $\mathrm{E}$ such that

$\mathrm{CONN}_{\mathrm{G}-(\mathrm{x} ; \mathrm{y})}(\mathrm{u} ; \mathrm{v})=\mathrm{CONN}_{\mathrm{G}}(\mathrm{u} ; \mathrm{v})$ for all $\mathrm{u} \in \mathrm{V}-\gamma_{c l}$ and a $\mathrm{v} \in \gamma_{c l}(\mathrm{G})$. Here $\gamma_{c l}(\mathrm{G})$ represent minimum dominate set

Definition 8.17. (Global Domination) A domination set $D$ of a graph $G=(V, E)$ is a global dominating set if $D$ is also dominating set of $\mathrm{G}$. The global domination number $\gamma_{g}(\mathrm{G})$ of graph $\mathrm{G}$ is the minimum cardinality of a connected dominating set.

Definition 8.18. The bondage number $\mathrm{b}_{\mathrm{g}}(\mathrm{G})$ of a fuzzy graph $\left.\mathrm{G}(\mathrm{V} ; \mathrm{E}, \sigma, \mu)\right)$ is minimum number of fuzzy arcs among all sets of $\operatorname{arcs} \mathrm{X}=(\mathrm{x}, \mathrm{y})$ sub set of E such that

$\mathrm{CONN}_{\mathrm{G}-(\mathrm{x} ; \mathrm{y})}(\mathrm{u} ; \mathrm{v})<\mathrm{CONN}_{\mathrm{G}}(\mathrm{u} ; \mathrm{v})$ for all $\mathrm{u} \in \mathrm{V}-\gamma_{g}$ and a $\mathrm{v} \in \gamma_{g}(\mathrm{G})$. Here $\gamma_{g}(\mathrm{G})$ represent minimum dominate set 
Definition 8.19. The non-bondage number $\mathrm{b}_{\mathrm{cln}}(\mathrm{G})$ of a fuzzy graph $\left.\mathrm{G}(\mathrm{V} ; \mathrm{E}, \sigma, \mu)\right)$ is maximum number of fuzzy arcs among all sets of $\operatorname{arcs} X=(x, y)$ sub set of $E$ such that

$\mathrm{CONN}_{\mathrm{G}-(\mathrm{x} ; \mathrm{y})}(\mathrm{u} ; \mathrm{v})=\mathrm{CONN}_{\mathrm{G}}(\mathrm{u} ; \mathrm{v})$ for all $\mathrm{u} \in \mathrm{V}-\gamma_{g}$ and $\mathrm{a} \mathrm{v} \in \gamma_{g}(\mathrm{G})$. Here $\gamma_{g}(\mathrm{G})$ represent minimum dominate set

Theorem 8.20. If $\mathrm{G}$ be a fuzzy cycle graph then

with $\mathrm{p} \geq 4$

$$
b_{g n}(\bar{G})+b_{g n}(G) \leq \frac{p(p-3)}{2}
$$

Theorem 8.21. For any fuzzy graph $\mathrm{G}$,

Remark: $b_{g n}(\bar{G})+b_{g n}(G) \leq \frac{(p-1)(p-3)}{2}+q$

$$
b_{g n}(\bar{G})+b_{g n}(G) \leq \frac{(p-1)(p-3)}{2}
$$

\section{Fuzzy Graceful Graphs}

Definition 9.1. Let $\mathrm{G}(\mathrm{V}, \mathrm{E}, \sigma, \mu)$ be a R-fuzzy graph and it is satisfied M-fuzzy graph and which admit following condition is called graceful graph.

- $\sigma: \mathrm{V} \rightarrow\left\{[0,1]-\mathrm{P}_{\mathrm{n}}[0,1]\right\}$ is $1-1$

- $\quad \mu: \mathrm{Vx} \mathrm{V} \rightarrow\left\{[0,1]-\mathrm{P}_{\mathrm{n}}[0,1] \backslash\{0\}\right\}$ is $1-1$ and onto

$P_{n}=\{$ Partition of $[0,1]$ by open interval of length $1 / n\}$ where $n=$ number of arcs

Theorem 9.2.

The $\left(\mathrm{n} * \mathrm{C}_{4}\right) * \mathrm{P}_{1}$ is graceful graph and show on below Generalization of $\left(\mathrm{n} * \mathrm{C}_{4}\right) * \mathrm{P}_{1}$.

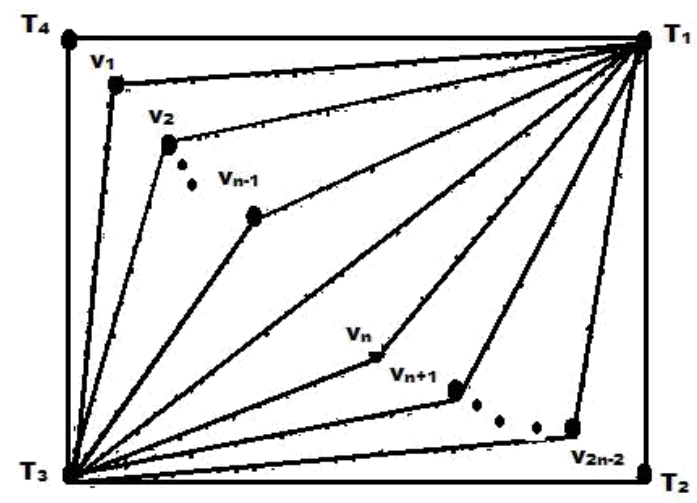

Figure 5: Graceful Graph

Proof.

$\mathrm{P}_{1}=$ Path of length 1 ,

$\mathrm{N}=$ Number of square.

$\mathrm{C}_{4}=$ Cycle of 4 nodes $: \mathrm{q}=$ Number of arcs

$\mathrm{f}\left(\mathrm{T}_{1}\right)=0: \mathrm{f}\left(\mathrm{T}_{2}\right)=1,: \mathrm{f}\left(\mathrm{T}_{3}\right)=\frac{1}{q},: \mathrm{f}\left(\mathrm{T}_{4}\right)=1-\frac{2}{q}: \mathrm{f}\left(\mathrm{v}_{1}\right)=1-\frac{4}{q}: \mathrm{f}\left(\mathrm{v}_{\mathrm{n}}\right)=\frac{3}{q}$.

$\mathrm{f}\left(\mathrm{v}_{\mathrm{i}}\right)=\left\{\begin{array}{lr}f\left(v_{i-1}\right)-\frac{4}{q} & \text { for } i=2,3, \ldots n-1 \\ f\left(v_{i-1}\right)+\frac{4}{q} & \text { for } i=n+1, n+2 \ldots .2(n-1)\end{array}\right.$ 
Example: $n=4$

Figure 6: Grace full graph

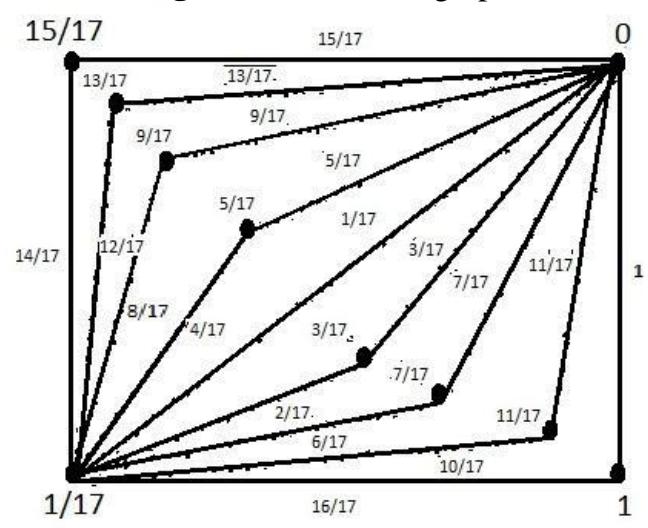

Theorem 9.3. The $n^{*} P_{5}$ is graceful graph and show on below Generalization of $n * P_{5}$.

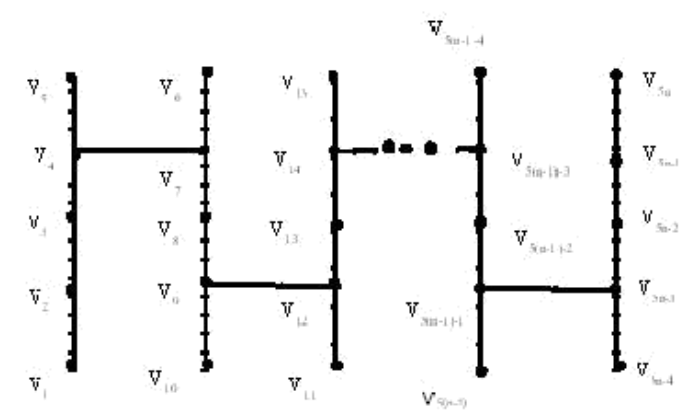

Figure 7: Graceful Graph

Proof.

$\mathrm{n}=$ number of $\mathrm{P}_{5}$

$\mathrm{q}=$ number of arcs

$\mathrm{f}\left(\mathrm{v}_{1}\right)=0: \mathrm{f}\left(\mathrm{v}_{2}\right)=1: \mathrm{f}\left(\mathrm{v}_{3}\right)=\frac{1}{q}$

If $n=$ odd:

$\mathrm{f}\left(\mathrm{v}_{\mathrm{i}}\right)=\left\{\begin{array}{cr}f\left(v_{i-2}\right)+\frac{1}{q} & \text { for } i=5,7, \ldots 5 n \\ f\left(v_{i-2}\right)-\frac{1}{q} & \text { for } i=4,6, \ldots 5 n-1\end{array}\right.$

If $\mathrm{n}=$ even

$\mathrm{f}\left(\mathrm{v}_{\mathrm{i}}\right)= \begin{cases}f\left(v_{i-2}\right)+\frac{1}{q} & \text { for } i=5,7, \ldots 5 n-1 \\ f\left(v_{i-2}\right)-\frac{1}{q} & \text { for } i=4,6, \ldots 5 n\end{cases}$ 


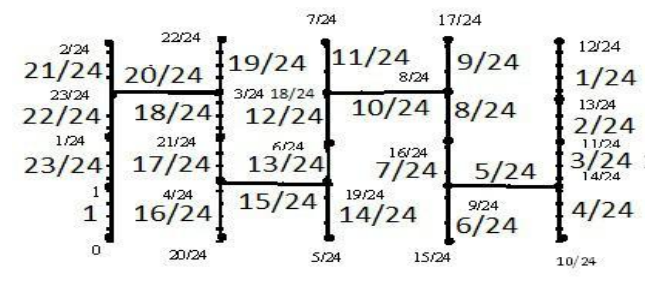

Example

Figure 8: Graceful Graph

\section{Graph Extension}

If we take maximum of Co-bondage number set should given dominate number is one but that graph not complete but complete has dominate number is one .so we make graph extendable to complete graph under finite extension.

Definition 10.1. Let $\mathrm{G}$ be a strong and simple fuzzy graph .Extension on $\mathrm{G}$ is defined as follows: In the first extension ,add one $\operatorname{arc}\left(\right.$ take cense as in co-bondage arc) to $G$ denoted as $G^{1}, G^{1}=G \cup\left\{e_{1}\right\}$.In second extension add two edges on $\mathrm{G}^{1}$ denoted by $\mathrm{G}^{2}, \mathrm{G}^{2}=\mathrm{G} \cup\left\{\mathrm{e}_{1}, \mathrm{e}_{2}, \mathrm{e}_{3}\right\}$ and so on until no such an extension remains, here $\mu\left(e_{i}=(u, v)\right)=\operatorname{Max}\{(u, w),(u ; x)\}$ or $\operatorname{Max}\{(w, v),(x, v)\}$, for any $w, x$ in $V$.

Definition 10.2: let $\mathrm{G}$ be a any fuzzy graph and if $\mathrm{G}^{\mathrm{k}} \cong K_{p}$ then $\mathrm{G}$ is said to be a fuzzy complete graph and $\mathrm{k}$ is known as the order of extension.

Theorem 10.3. Let $\mathrm{G}$ be a graph and let $\mathrm{G}^{\mathrm{k}}=\mathrm{G} \cup\left\{\mathrm{e}_{1}, \mathrm{e}_{2}, \mathrm{e}_{3, .} \mathrm{e}_{\mathrm{m}}\right\}$.If $\mathrm{G}^{\mathrm{k}}$ is the $\mathrm{k}^{\text {th }}$ extension of $\mathrm{G}$ then $m=\frac{k(k+1)}{2}$ Proof. Given $\mathrm{G}$ is a graph with $\mathrm{q}$ arcs , then the first extension should add one arc and second extension add two arcs with first extension, so total $\mathrm{G}$ has $\mathrm{q}+(1+2)$ arcs at end of second extension,.

Similarly $3^{\text {rd }}$ extension will add 3 arcs, then total $G$ has $\mathrm{q}+(1+2+3)$ arcs and so on $\mathrm{k}^{\text {th }}$ extension $\mathrm{G}$ has $\mathrm{q}+(1+2+3+\ldots+\mathrm{k})$.

We can written $\mathrm{G}^{\mathrm{k}}=\mathrm{GU}\left\{\mathrm{e}_{1} ; \mathrm{e}_{2} ;:: \mathrm{e}_{\mathrm{m}}\right\}$ where $\mathrm{m}$ is total number of arcs should added to $\mathrm{G}$. We know that sum first k natural numbers is $\frac{k(k+1)}{2}$ so $m=\frac{k(k+1)}{2}$

Example $\mathrm{G}^{2}$ is fuzzy complete extendable of graph $\mathrm{G}$ and extension order 2
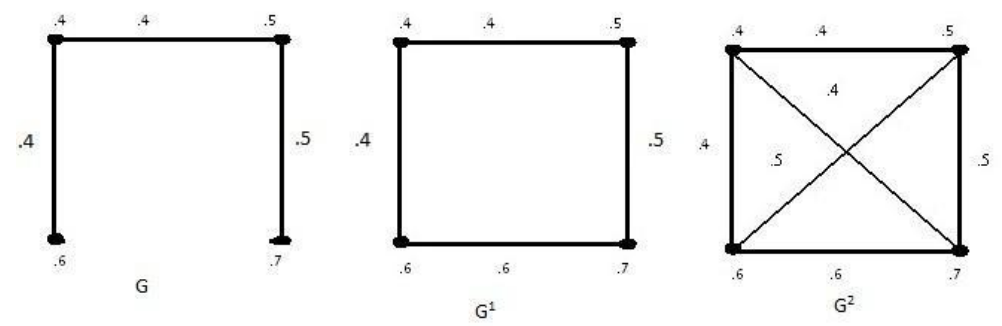

Figure 9: Graph Extension

Theorem 10.4. Let $\mathrm{G}$ be a path with $\mathrm{p}$ nodes then $\mathrm{G}$ is fuzzy complete extendable with $\mathrm{p}-2$ order extension.

Proof : Given $\mathrm{G}$ is path with $\mathrm{p}$ nodes, so $\mathrm{G}$ has $\mathrm{p}-1$ arcs, then we need $\frac{p(p+1)}{2} \operatorname{arcs}$ require to $\mathrm{G}$ will becomplete extendable using above theorem 10.3 with $\mathrm{k}=\mathrm{p}-2$, so $\mathrm{G}$ has order extension $\mathrm{p}-2$.

Theorem 10.5. Let $\mathrm{G}$ be a cycle graph then $\mathrm{G}$ is not fuzzy complete extendable

Definition 10.6. Let $\mathrm{G}$ be a graph which is not fuzzy complete extendable. Let $\mathrm{r}$ be the maximum possible number of extension in $G$ such that $G^{r}$ is not complete. Then the deficiency number of $G$ is defined as the number of arcs required to make $\mathrm{G}^{\mathrm{r}}$ complete.

Example take Figure $-10 \mathrm{G}^{1}$ is not complete,so add one arc then $\mathrm{G}^{1}$ is complete so deficiency number is1

Theorem 10.7.Let $\mathrm{G}$ be a cycle graph with $\mathrm{p} \geq 4$ nodes, then ( $\mathrm{p}-3$ ) is deficiency number of $\mathrm{G}$

Proof: 
Given graph $\mathrm{G}$ is cycle then $\mathrm{G}$ is not complete extendable by theorem and we know that $\mathrm{G}$ has $\mathrm{p}$ arcs. If applied $(\mathrm{p}-3)^{\text {th }}$ extension in $\mathrm{G}$ then $\mathrm{G}$ has $\frac{p^{2}-3 p+6}{2}$ arcs still $\mathrm{G}$ is not complete extendable so ( $\mathrm{p}-3$ ) arcs required to make $\mathrm{G}^{\mathrm{p}-3}$ is complete extendable clearly $(\mathrm{p}-3)$ is deficiency number of $\mathrm{G}$

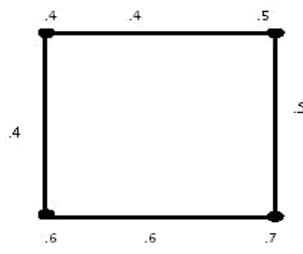

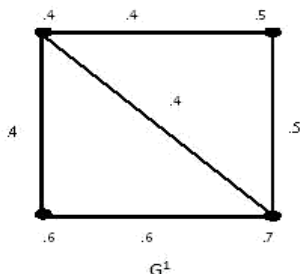

Figure 10:

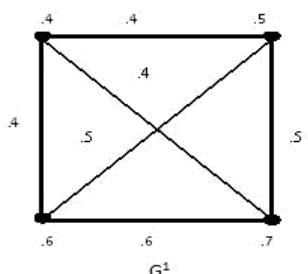

\section{Conclusion}

Above non bondage value $(\neq 0)$ is not true for all graphs because $\mathrm{K}_{1 ; \mathrm{n}}$ or star graph and $\mathrm{P}_{3}$ nonbondage value is 0 and also bondage number is equal to 1 for such above graphs and co-bondage of complete graph is also 0 (not determine)

\section{References}

[1]. T.L. Baldwin, L. Mili, M.B. BoisenJr, R. Adapa, Power system observability with minimal phasor measurement placement, IEEE Trans. Power Systems 8 (1993) 707715

[2]. E.J.Cockayne, B.L.Hartnell, S.T. Hedetniemi and R. Laskar, E cient domination in graphs, Technical Report 558 Clemson University, department of mathematical Sciences (1988)

[3]. E.J. Cockayne and S.T Hedetniemi; Towards a theory of domination in graphs, Networks,247-261 (1977)

[4]. J.F .Fink, M.S.Jacobson, L.F .Kinch and J.Roberts; The bondage number of graph, Discrete Math., 86, 47-57 (1990).

[5]. Gerard Jennhwa Chang, Paul Dorbec „, MickaelMontassier, AndrRaspaud:Generalized power dom-ination of graphs,Discrete Applied Mathematics 160 (2012) 16911698

[6]. F. Harary: Graph theory, Addison Wesley, Reading, Massachusetts (1963)

[7]. R.JahirHussain and R.M. Karthikkeyan: Characterization of fuzzy non- bondage number of fuzzy graphs. Mathematical Sciences int., Research Journal vol4 issue 2 ISSN 2278-8697

[8]. V.R. Kulli and B. Janakiram; The non-bondage number of a graph, New York Acadency of Science, (1996)

[9]. A.Rosenfeld. Fuzzy graphs, InFuzzysets and their applications to Cognitive and Decision. Eds. Aca-demic press, New York (1975)77-95.

[10]. K .R. Sandeep Narayan and M.S. Sunitha ; Connectivity in a Fuzzy Graph and its complement ICSRS Publication ,2012

[11]. Sunil Mathew, Sunitha M.S; Fuzzy Graphs: Basic Concepts and Applications, Lap Lambert Academic Publication.

[12]. G. Suresh Singh, Sunitha Grace Zacharia : Some Results On Completely Extendable And Weighted Extendable Graphs International Journal Of Mathematical Archive-2016, 92-97 Theory of Domination in Graphs, MRI Lecture Notes Math. I (1979). 